\title{
Regards sur les cheminots et leurs métiers
}

\section{François Caron}

\section{OpenEdition}

\section{Journals}

Édition électronique

URL : https://journals.openedition.org/rhcf/234

DOI : 10.4000/rhcf.234

\section{Éditeur}

Rails \& histoire

Édition imprimée

Date de publication : 1 décembre 2007

Pagination : 7-10

ISSN : 0996-9403

\section{Référence électronique}

François Caron, "Regards sur les cheminots et leurs métiers », Revue d'histoire des chemins de fer [En ligne], 36-37 | 2007, mis en ligne le 10 mai 2011, consulté le 22 avril 2022. URL : http:// journals.openedition.org/rhcf/234 ; DOI : https://doi.org/10.4000/rhcf.234 


\title{
Regards sur les cheminots et leurs métiers
}

\author{
François Caron \\ Historien, professeur émérite à l'université de Paris-Sorbonne \\ (Paris IV), président du Comité scientifique de l'AHICF
}

Pour analyser les relations entre un métier et son image, nous tenterons d'abord de définir les fondements constitutifs des cultures de métier en les replaçant dans le contexte des communautés de travail, entreprises ou administrations dans lesquelles ils fusionnent, et de nous interroger ensuite sur la nature et la validité des regards portés sur ces métiers dans le cadre de ces communautés de travail.

\section{Métiers et communautés}

Les métiers sont le résultat d'une construction historique complexe propre à chacun d'eux. Elle repose sur trois fondements étroitement dépendants les uns des autres. Au cœur du système se trouve l'expérience technique. Celle-ci réalise la synthèse d'un ensemble de caractéristiques originales comme les gestes, dans leur infinie diversité, les savoirs et les savoir-faire, le degré d'ingéniosité nécessaire à la pratique du métier, ou encore leur degré de pénibilité et de dangerosité. Ces différentes caractéristiques évoluent, parfois très rapidement, en fonction des changements techniques apparus au sein du métier ou venus d'ailleurs. Ils exigent de l'ouvrier ou de l'artisan une capacité d'adaptation permanente. L'expérience technique est, par elle-même, constructrice de systèmes de valeurs originaux. Mais d'autres facteurs interviennent dans leur élaboration et leur évolution. Les cultures de métier sont étroitement dépendantes de l'environnement dans lequel elles se sont épanouies. Yves Lequin a montré le rôle majeur des origines géographiques et sociologiques dans la formation des cultures des métiers Rhône-alpins. Le métier réalise ainsi l'intégration dans un ensemble unifié d'expériences antérieures. Il faut insister en troisième lieu sur le rôle des modèles institutionnels adoptés par les organisations qui emploient les artisans et les ouvriers détenteurs de ces savoir-faire. Ils concernent aussi bien les modes de transmission des savoirs, fondés sur les relations directes entre les générations ou sur un apprentissage et un enseignement formalisés, que la construction des systèmes hiérarchiques ou la définition des normes et des règles écrites ou tacites qui s'imposent à tous. 
Sur la base de ces trois fondements se construisent des cultures de métier définies par des systèmes de valeurs et des pratiques communes. Les organisations et les entreprises, et tout particulièrement les entreprises ferroviaires, doivent réaliser la fusion de savoir-faire et de cultures de métier très différents les uns des autres. Les métiers ainsi regroupés ont dans le cas des entreprises de chemin de fer des caractéristiques très nettement affirmées. C'est en fait le réseau qui constitue l'élément unificateur de ces cultures diverses. Emile Zola a bien illustré ce phénomène dans le roman La Bête humaine et Raoul Dautry a utilisé ce concept dans son effort de construction d'une identité d'entreprise 7sur le réseau de l'État entre 1928 et 1937, effort dont s'inspirèrent les dirigeants de la SNCF à partir de 1938. Le réseau est un organisme en mouvement perpétuel, orienté vers la réalisation d'un but commun, la régularité d'un service assuré quotidiennement et sans interruption. Cette performance ne peut être réalisée que par un effort commun fondé non seulement sur la complémentarité des compétences mais aussi sur la bonne coordination des actions et des gestes de chacun des acteurs. Elle repose sur la définition de normes et de règles, qui s'imposent à tous sans difficulté. Mais entre les identités de métier et les identités de communautés et de réseaux peuvent apparaitre des tensions ou des lignes de fracture importantes. Les mécaniciens, les ouvriers d'atelier ou les agents des trains n'ont cessé d'exprimer leurs particularités aussi bien sur les lieux de travail que dans l'action syndicale.

Pourtant, il semble possible de décrire un système de valeurs propre au monde des cheminots combinant le sens aigu de la responsabilité lié à l'obsession de la sécurité, la parfaite rigueur dans l'exécution des tâches liée à l'obligation d'exactitude et de régularité du service ou encore l'acceptation d'une autorité hiérarchique forte, à condition que sa compétence ne puisse être mise en doute. On peut aussi décrire des pratiques de métier marquées par une forte propension à la syndicalisation et à la grève, une conscience professionnelle et politique tout aussi forte, une activité associative intense, un attachement très profond au réseau auquel on appartient ainsi qu'à son territoire. Mais les cultures de réseau connaissent de considérables variations dans leurs manifestations particulières d'un pays à l'autre ou d'un réseau à l'autre.

\section{Les regards}

Il faut établir une nette distinction entre le regard de soi et le regard des autres. Le regard de soi se construit empiriquement sur la base d'une expérience intergénérationnelle, souvent difficile à supporter et rugueuse. Mais les rites initiatiques nous sont mal connus. Les lieux 
de transmission de ces valeurs et des pratiques sont divers. Le lieu de travail est le plus important. Mais il n'est pas le seul. Il faut y ajouter divers lieux de sociabilité et de rencontres ou d'action militante. Entre l'expérience personnelle des nouveaux embauchés et l'héritage transmis par les générations précédentes peut se produire un conflit difficile à gérer pour les premiers, ne serait-ce qu'en raison de la modification permanente des pratiques et des valeurs liées au changement tout aussi permanent des techniques et des modèles d'organisation. Les valeurs issues de l'héritage peuvent subir une obsolescence irrémédiable. L'image de soi peut ainsi s'en trouver ainsi entièrement brouillée.

Le regard des autres se construit de manière imparfaite. Il est par essence biaisé. Il n'est jamais neutre, même lorsqu'il revendique un statut scientifique. Que l'on songe aux publicités à l'embauche diffusées par la SNCF mais aussi aux innombrables images instrumentalisées du cheminot. On peut évoquer le parfait républicain loué par Gambetta et par Victor Hugo, le militant syndical transformé en avant-garde du prolétariat ou en instrument de la lutte des classes par les syndicalistes révolutionnaires ou par les syndicalistes communistes, l'ouvrier modèle décrit par la presse de droite, le héros de la reconstruction devenu l'instrument du redressement de la France à la Libération. On pourrait allonger indéfiniment la liste de ces instrumentalisations à but idéologique ou politique. L'image littéraire du cheminot n'est pas moins biaisée, même sous la plume d'Emile Zola obligé à forcer le trait, malgré l'immense travail de documentation qu'il réalisa. Car l'image littéraire du cheminot est contaminée par l'image littéraire du chemin de fer, symbole de modernité pour les uns, instrument d'acculturation pour les autres. L'image à prétention scientifique que nous proposent les sociologues et les historiens est, elle aussi, une image interprétée en fonction de choix conceptuels avoués ou inavoués. Le cheminot devient l'instrument d'une démonstration, l'acteur d'une vision particulière de l'histoire et de la société de telle ou telle époque. Il s'agit pour les uns de montrer la validité du concept de lutte des classes, pour les autres de défendre celui de service public, pour d'autres encore de vanter les vertus de certaines formes de paternalisme, pour tous de construire une image idéologiquement signifiante du cheminot. Mon expérience personnelle est démonstrative à cet égard. Lorsque j'ai confronté l'image du cheminot que j'avais élaborée à travers la lecture de la presse syndicale, image qui correspondait assez bien à la vision préalable que j’avais des relations sociales au sein des compagnies, et celle qui résulta du dépouillement réalisé par moi-même et par Georges Ribeill de l'enquête par questionnaires que j’avais menée auprès de cheminots retraités, 
il m'a fallu modifier assez radicalement la première de ces deux visions. C'est pourquoi, aujourd'hui encore, je crois en la supériorité de la méthode des questionnaires, qui me semble pouvoir atteindre une plus grande objectivité que les autres méthodes et qui a malheureusement été très largement abandonnée.

Il ne faut toutefois pas désespérer de pouvoir construire une image des différents métiers susceptible de se rapprocher de leur nature réelle, c'est-à-dire de leur vécu authentique. Cette construction doit prendre en compte trois préceptes essentiels. Tout d'abord, c'est prioritairement à travers les pratiques techniques que se définit l'identité du métier. Rien n'est possible sans une perception correcte des réalités concrètes et quotidiennes propres à chaque métier. L'observation et l'analyse des gestes accomplis et des procédures utilisées par les artisans et les ouvriers furent la base de la méthode utilisée par les encyclopédistes pour décrire et découvrir les secrets des métiers. Cette méthode a conservé toute sa valeur. En second lieu, la description et la compréhension des réalités organisationnelles et sociales exigent un effort d'objectivité et de distanciation que très peu d'observateurs sont capables d'accomplir. De ce point de vue l'approche ethnologique est sans doute de loin préférable à l'approche sociologique. Mais un questionnaire bien conçu peut aussi, nous l'avons dit, permettre d'approcher au plus près la réalité vécue des expériences professionnelles. Enfin, il faut rappeler qu'entre les différents regards, interprofessionnels ou interdisciplinaires, s'établissent des interférences qui permettent de construire une image complexe du monde des métiers en mettant à profit le croisement de ces regards. 